\title{
Dividend policy - Overview of the development of the explanatory approaches
}

\author{
Serkan Akbay, M.Sc. and Prof. Dr. Dr. habil. Clemens Jäger \\ UCAM, Murcia and FOM, Essen
}

\begin{abstract}
Companies compare the dividend payout with the reinvesting policy into the company. At the same time, it is not comprehensible to note that dividends are paid and simultaneous an increasing of capital by raising new capital or acquire new capital in form of debt (Easterbrook, 1984, p. 650). Therefore, it is necessary to deal with the dividend policy. Since the irrelevance theory have been developed by Miller and Modigliani (1961), further approaches have been followed. The assumptions of the theory (no tax, no transaction costs, rational behavior, no information asymmetries, costless access to information and no influence on price changes through a buyer or seller) were regular reasons to criticize the theory (Miller and Modigliani, 1961, p. 412). The further approaches resulted from the elimination of individual assumptions of the irrelevance theory. The poster presentation deal with the problem of several explanatory approaches and provide an overview of the approaches of the dividend policy in order to support answering of further research questions of finance.
\end{abstract}

Keywords: Irrelevance theory, Asset pricing, Financing policy, Payout policy, Value of Firms 